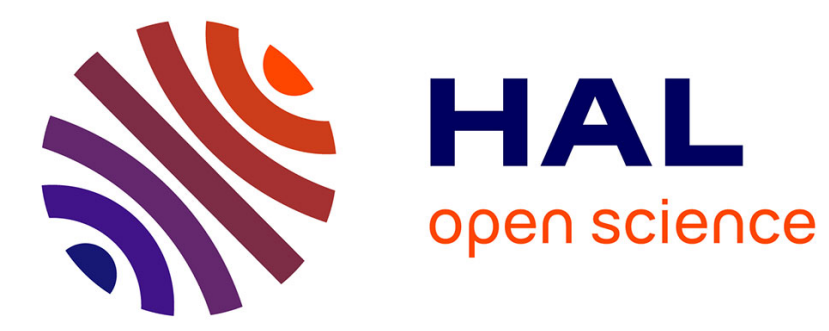

\title{
Enhanced Two-Photon Absorption with Novel Octupolar Propeller-Shaped Fluorophores Derived from Triphenylamine
}

Laurent Porrès, Olivier Mongin, Claudine Katan, Marina Charlot, Thomas Pons, Jerome Mertz, Mireille Blanchard-Desce

\section{To cite this version:}

Laurent Porrès, Olivier Mongin, Claudine Katan, Marina Charlot, Thomas Pons, et al.. Enhanced Two-Photon Absorption with Novel Octupolar Propeller-Shaped Fluorophores Derived from Triphenylamine. Organic Letters, 2004, 6 (1), pp.47-50. 10.1021/ol036041s . hal-01416756

\section{HAL Id: hal-01416756 \\ https://hal-univ-rennes1.archives-ouvertes.fr/hal-01416756}

Submitted on 14 Dec 2016

HAL is a multi-disciplinary open access archive for the deposit and dissemination of scientific research documents, whether they are published or not. The documents may come from teaching and research institutions in France or abroad, or from public or private research centers.
L'archive ouverte pluridisciplinaire HAL, est destinée au dépôt et à la diffusion de documents scientifiques de niveau recherche, publiés ou non, émanant des établissements d'enseignement et de recherche français ou étrangers, des laboratoires publics ou privés. 


\section{Enhanced Two-Photon}

\section{Absorption with Novel Octupolar Propeller-Shaped Fluorophores Derived from Triphenylamine}

Laurent Porrès ${ }^{a}$ Olivier Mongin ${ }^{a}$ Claudine Katan ${ }^{a}$ Marina Charlot, Thomas Pons, ${ }^{b}$ Jerome Mertz ${ }^{b}$ and Mireille Blanchard-Desce ${ }^{\star^{a}}$

${ }^{a}$ Synthèse et ElectroSynthèse Organiques (CNRS, UMR 6510), Institut de Chimie, Université de Rennes 1, Campus de Beaulieu, Bât. 10A, F-35042 Rennes Cedex,

France.

${ }^{b}$ Neurophysiologie et Nouvelles Microscopies (INSERM EPI 00-02, CNRS FRE 2500), Ecole Supérieure de Physique et Chimie Industrielles, 10 rue Vauquelin, F-75231 Paris Cedex 05, France. mireille.blanchard-desce@univ-rennes1.fr

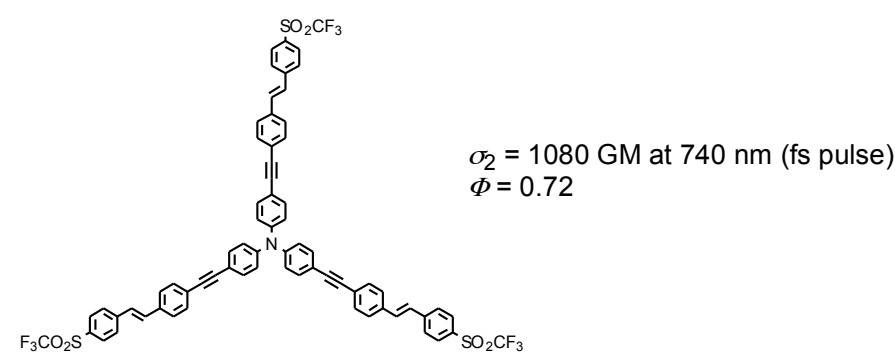

Novel octupolar fluorophores derived from the symmetrical functionalization of a triphenylamine core with strong acceptor peripheral groups via phenylene-ethynylene linkers have been synthesized and shown to exhibit high fluorescence quantum yields, very large TPA cross-sections in the red-NIR region and suitable photostability.

Molecular two-photon absorption (TPA) has attracted growing interest over recent years owing to the many applications it offers both in material science and in biological imaging. These include microfabrication, ${ }^{1}$ 3D optical data storage, ${ }^{2}$ optical power limitation, ${ }^{3}$ localized photodynamic therapy, ${ }^{4}$ and two-photon laser scanning fluorescence imaging. 5 These applications call for the design of specifically engineered compounds displaying enhanced TPA cross-sections. In the case of two-photon excited fluorescence (TPEF) microscopy, high performance fluorophores must exhibit both high fluorescence quantum yields $(\phi)$ and large TPA cross-sections $\left(\sigma_{2}\right)$ in the red-NIR range (700-1200 $\mathrm{nm})$, corresponding to the biological optimal window for reduced photodamage. ${ }^{5}$ Photostability is also an important feature to consider for TPEF-based applications.

The optimization of molecular TPA has largely focused on one-dimensional dipolar ${ }^{6,7}$ or quadrupolar ${ }^{3,7,8}$ structures, and so far only little attention has been devoted to the design of optimized octupolar structures, ${ }^{9}$ although it has been realized that increased dimensionality and branched structures $^{10,11}$ could lead to highly effective multiphoton absorption. In this perspective, we have investigated a series of novel three-branched octupolar fluorophores with the aim of optimizing their TPEF cross-section $\left(\sigma_{2} \phi\right)$ in the NIR region, as well as ensuring suitable photostability. 
Our trigonal derivatives are derived from the symmetrical functionalization of an electron-donating triphenylamine core with three conjugated branches (Scheme 1) bearing electron-withdrawing (A) end-groups (12-15). Although octupolar derivatives based on triphenylamine cores have been shown to lead to high quadratic polarizabilities, ${ }^{12}$ only few examples of such derivatives have been shown to display large TPA crosssection, ${ }^{\text {a-c }}$ calling for further engineering of the basic structures.

To examine the role of octupolar symmetry, we also have investigated a structurally-related analogue bearing only electron-releasing D peripheral groups (11). Following the same line of reasoning, we have selected strong acceptor peripheral groups using in particular the triflyl moiety (compounds 13,15 ), a powerful acceptor, ${ }^{13}$ which has not been considered yet in molecular engineering of TPA. Rigid (11-13) or semi-rigid $(\mathbf{1 4}, \mathbf{1 5})$ conjugated rods built from phenylene-ethynylene and phenylene-vinylene units were used to allow Intramolecular Charge Transfer (ICT) to take place between the core and the peripheral groups while maintaining fluorescence. In order to enhance the TPA cross-section, we have investigated molecules of increasing size from 2.9 to $4.3 \mathrm{~nm}$ in diameter. B3LYP ab-initio calculations indicate that the molecules adopt a propellershaped structure (Figure 1), the core nitrogen being trigonal and the conjugated branches twisted by about $40^{\circ}$.

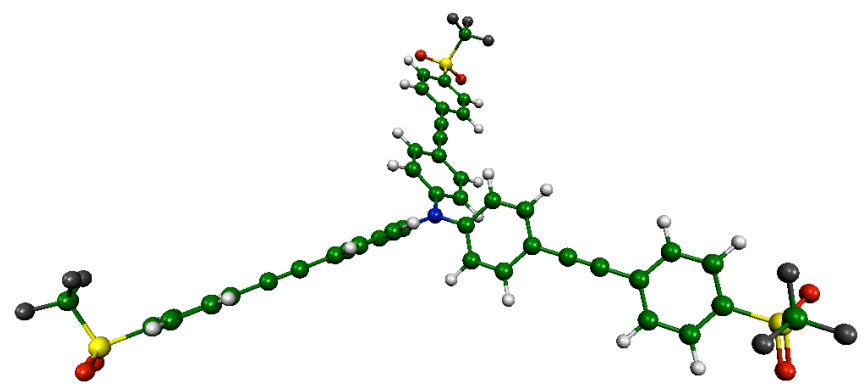

Figure 1. B3LYP optimized geometry of fluorophore 13.

The synthesis of these fluorophores is based on the three-fold $\operatorname{Pd}(0)$-catalyzed cross-coupling reaction of the nitrogen-cored building block 10 (Scheme 1) with aromatic iodide $\left(\mathbf{1},{ }^{14} \mathbf{6}, \mathbf{7}\right)$ or bromide $\left(\mathbf{2}^{15}-\mathbf{3}^{16}\right)$ derivatives. The synthesis of the triphenylamine reagent $\mathbf{1 0}$ was achieved by triiodination $^{17}$ of triphenylamine, followed by a triple Sonogashira coupling with ethynyltrimethylsilane. The extended building blocks 6 and 7 were obtained from the halo derivatives $\mathbf{4}$ and $\mathbf{5}$, respectively, in a three-step sequence (Michaelis-Arbuzov reaction, oxidation and Horner-Wadsworth-Emmons condensation with 4-iodo- benzaldehyde). All new fluorophores have been fully characterized by NMR, HRMS and elemental analysis data.

The photophysical properties of the new series of trigonal fluorophores are shown in Table 1 and Figure 2.

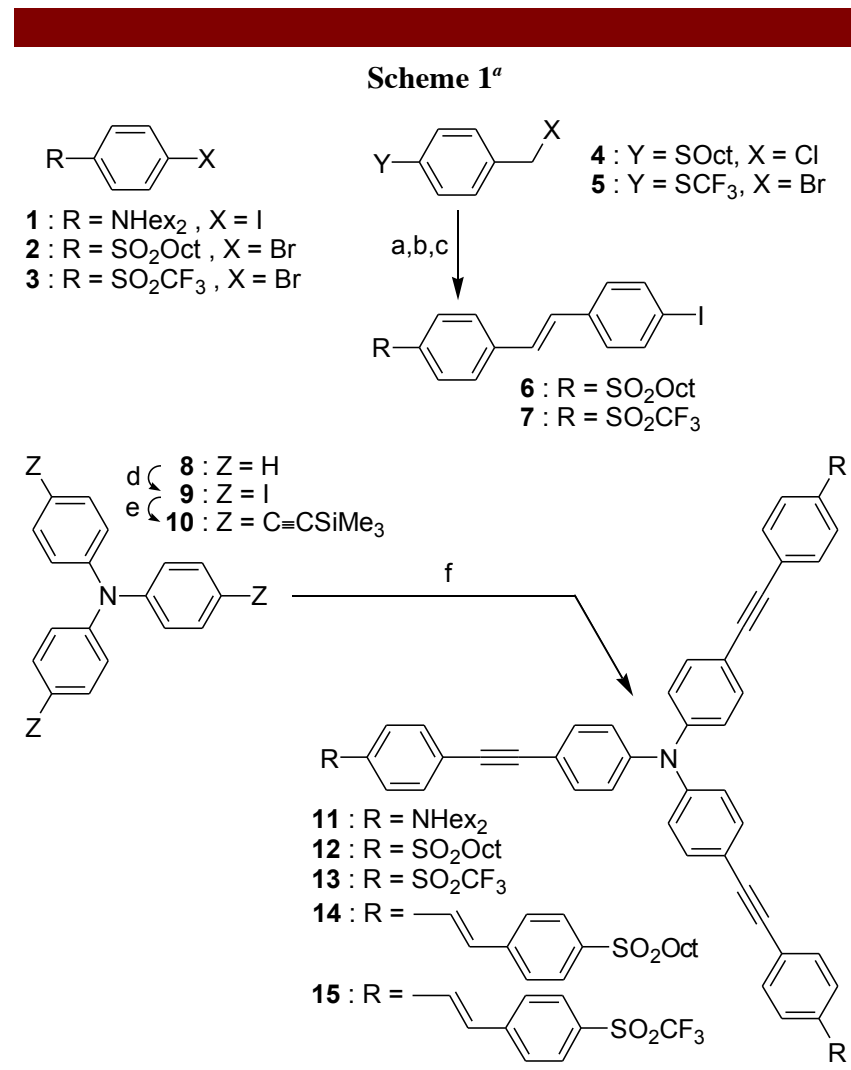

${ }^{a}$ Reagents and conditions: (a) $\mathrm{P}(\mathrm{OEt})_{3}$, reflux, $10 \mathrm{~h}(80-84 \%)$; (b) $\mathrm{H}_{2} \mathrm{O}_{2}, \mathrm{AcOH}$, reflux, $4 \mathrm{~h}(77-82 \%)$; (c) 4-iodobenzaldehyde, $\mathrm{NaH}, \mathrm{THF}, \mathrm{rt}, 15 \mathrm{~h}$ (51-61\%); (d) KI (2 equiv), $\mathrm{KIO}_{3}$ (1 equiv), $\mathrm{AcOH}, 85{ }^{\circ} \mathrm{C}, 5 \mathrm{~h}(88 \%)$; (e) $\mathrm{HC} \mathrm{CSiMe}_{3}, \mathrm{Pd}\left(\mathrm{PPh}_{3}\right)_{2} \mathrm{Cl}_{2}, \mathrm{CuI}$, toluene/Et ${ }_{3} \mathrm{~N}, 40{ }^{\circ} \mathrm{C}, 2.5 \mathrm{~h}(96 \%)$; (f) $\mathrm{TBAF}, \mathrm{R}-\pi-\mathrm{X}(\mathbf{1 - 3}, 6$ or 7, 3.5 equiv), $\mathrm{Pd}_{2} \mathrm{dba}_{3}, \mathrm{PPh}_{3}, \mathrm{CuI}$, toluene/ $\mathrm{Et}_{3} \mathrm{~N}, 35^{\circ} \mathrm{C}(72-89 \%)$.

We observe that all fluorophores display a broad absorption in the near UV-visible violet region and exhibit high fluorescence quantum yield (about 0.8) independently of their end-groups (D or A) or conjugated branch nature. In contrast their fluorescence lifetimes are significantly affected by the nature of the peripheral groups. We observe that the octupolar derivatives (12-15) display longer fluorescence lifetimes than the analogue bearing only donor peripheral groups (11). Interestingly, the powerful triflyl acceptor leads to a noticeable increase of the fluorescence lifetime, while an increase in the length of the branches by the addition of a phenylene-vinylene unit results in a decrease of the fluorescence lifetime.

Increasing the polarity of the solvent leads to a slight bathochromic shift of the absorption band of octupolar 
fluorophores (12-15), and to a more pronounced red shift in their emission band (Table 1). Such positive solvatochromic behavior can be related to an ICT phenomenon taking place between the fluorophore center and periphery. ${ }^{18,19}$
The TPA spectra of fluorophores 11-15 in the 740-950 $\mathrm{nm}$ range were determined by investigating their TPEF in solution according to the protocol described by Webb and coworkers $^{20}$ in the femtosecond regime. We note that

Table 1 Photophysical and Two-Photon Absorption Characteristics of Fluorophores 11-15.

\begin{tabular}{|c|c|c|c|c|c|c|c|c|c|c|}
\hline \multirow{2}{*}{ compd } & \multicolumn{2}{|c|}{$\lambda_{\mathrm{abs}}^{\mathrm{OPA}}(\mathrm{nm})^{a}$} & \multirow{2}{*}{$\log \varepsilon^{b}$} & \multicolumn{2}{|c|}{$\lambda_{\mathrm{em}}^{\mathrm{OPA}}(\mathrm{nm})^{c}$} & \multirow{2}{*}{$\begin{array}{l}\text { stokes shift } \\
\left(\mathrm{cm}^{-1}\right)^{b, d}\end{array}$} & \multirow{2}{*}{$\phi^{b, e}$} & \multirow{2}{*}{$\begin{array}{c}\tau \\
(\mathrm{ns})^{b, f}\end{array}$} & \multicolumn{2}{|c|}{$\sigma_{2}(\mathrm{GM})^{b, g}$} \\
\hline & toluene & $\mathrm{CHCl}_{3}$ & & toluene & $\mathrm{CHCl}_{3}$ & & & & at $2 \lambda_{\mathrm{abs}}^{\mathrm{OPA}}$ & at $740 \mathrm{~nm}$ \\
\hline 11 & 385 & 384 & 5.06 & 411 & 450 & 1600 & 0.77 & 0.88 & 15 & 30 \\
\hline 12 & 388 & 392 & 4.91 & 424 & 449 & 2200 & 0.77 & 1.27 & 150 & 160 \\
\hline 13 & 405 & 409 & 4.78 & 450 & 502 & 2500 & 0.78 & 1.49 & 420 & 495 \\
\hline 14 & 397 & 399 & 5.13 & 446 & 500 & 2800 & 0.79 & 1.07 & 660 & 1065 \\
\hline 15 & 408 & 409 & 4.97 & 473 & 542 & 3400 & 0.72 & 1.29 & 740 & 1080 \\
\hline
\end{tabular}

${ }^{a}$ One-photon absorption maximum ${ }^{b}$ In toluene. ${ }^{c}$ One-photon emission maximum. ${ }^{d}$ Stokes shift $=\left(1 / \lambda_{\text {abs }}-1 / \lambda_{\text {em }}\right) .{ }^{e}$ Fluorescence quantum yield relative to fluorescein in $0.1 \mathrm{~N} \mathrm{NaOH}$ as a standard $\left(\lambda_{\mathrm{ex}}=470 \mathrm{~nm}\right) .{ }^{f}$ Experimental fluorescence lifetime. ${ }^{g} \mathrm{TPA}$ cross-sections; $1 \mathrm{GM}^{\mathrm{T}}=10^{-50} \mathrm{~cm}^{4} . \mathrm{s} . \mathrm{photon}{ }^{-1}$; TPEF measurements were performed using a mode-locked Ti:sapphire laser delivering $80 \mathrm{fs}$ pulses at $80 \mathrm{MHz}$, calibrating with fluorescein.

the TPA spectra of the octupolar fluorophores 12-15 (Figure 3) exhibit a relative maximum close to twice $\lambda_{\text {abs }}^{\text {OPA }}$, indicating that the lowest energy excited-state is both onephoton and two-photon allowed. ${ }^{21}$

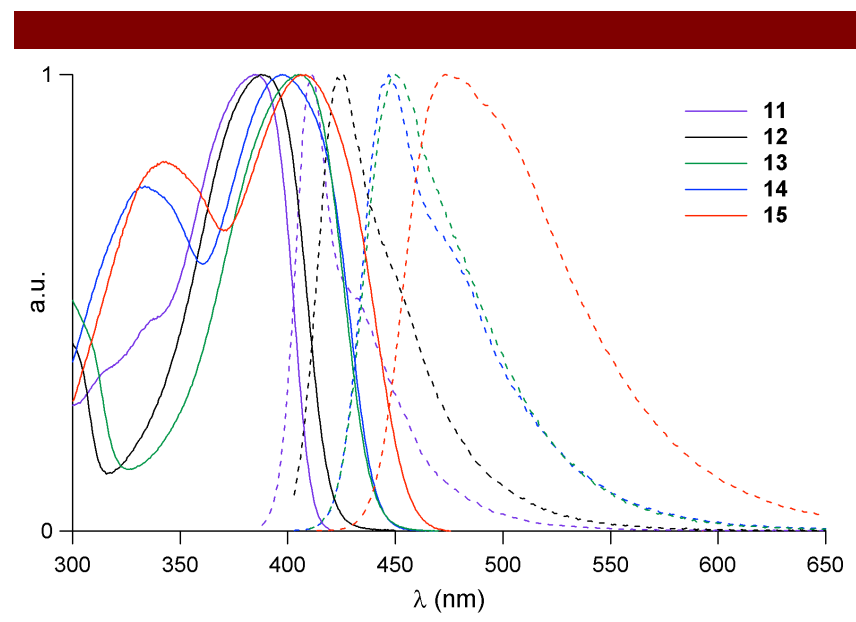

Figure 2. Normalized absorption and emission spectra of fluorophores 11-15 in toluene.

We note that the character of the end-groups significantly affects the TPA response. The tris-acceptor octupolar fluorophores display much larger TPA crosssections than their tris-donor counterpart (11). For instance, molecule 13 shows a TPA cross-section more than oneorder of magnitude larger than molecule $\mathbf{1 1}$ of similar size. Moreover we observe from the comparison of fluorophores 12 and 13 that increasing the acceptor character of the endgroup does lead to an important increase in the TPA crosssection (Figure 3), in correlation with a concomitant increase in the Stokes shift (Table 1) and a red shift of both the absorption and emission spectra (Figure 2).

By increasing the distance between the core and peripheral electroactive groups, we aimed at extending the multidimensional charge transfer phenomenon and increasing the nonlinear response. ${ }^{23}$ This strategy turned out to be effective, as observed from the comparison of fluorophores 12 and 14, which bear similar acceptor endgroups: increasing the molecular weight of the molecule by $30 \%$ (and increasing the size by about $50 \%$ ) leads to a $4-$ (respectively 6-) fold enhancement in the TPA crosssection at $2 \lambda_{\mathrm{abs}}^{\mathrm{OPA}}$ (respectively $740 \mathrm{~nm}$ ). This also leads to a red-shift and broadening of both absorption and emission bands (Figure 2), as well as to an increase in the Stokes shifts, consistent with an increase of the core-to-periphery ICT. A similar trend is noted when comparing fluorophores 13 and 15 (Table 1) - but to a lesser extent - while the main effect lies in the major broadening of the TPA spectrum towards the NIR region. As a result, the elongated octupolar fluorophore $\mathbf{1 5}$ bearing strong acceptor peripheral groups maintains sizeable TPA cross-section at $900 \mathrm{~nm}$ (Figure 3). Finally, we stress that the use of phenyleneethynylene linkers in the conjugated branches (in place of the more classical phenylene-vinylene linkers) leads to improved photostability, as indicated by the absence of photodegradation either upon pulsed-laser or prolonged lamp irradiation for derivatives $\mathbf{1 2}$ and $\mathbf{1 3}$.

In summary, we have designed and investigated novel multipolar fluorophores derived from a triphenylamine core. By enhancing the multidimensional ICT between the core and the peripheral groups, we produced fluorophores that combine very large TPA cross-sections in the red-NIR region, high fluorescence quantum yields and suitable photostability. This strategy led to octupolar fluorophores 


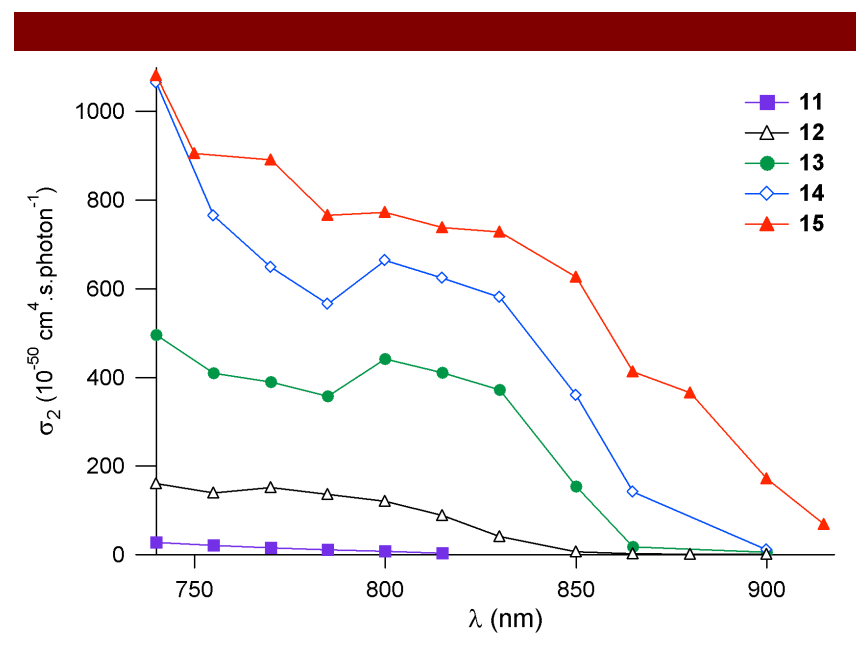

Figure 3. TPA spectra of fluorophores 11-15 in toluene.

that exhibit some of the highest TPA cross-sections measured to date in the NIR region and in the femtosecond regime. $^{24}$

Furthermore, our study provides evidence that the TPA cross-sections of such derivatives can be significantly enhanced in the NIR region with elongated derivatives bearing strong electron-withdrawing peripheral groups, leading to new directions for further engineering of their TPA properties. In particular by modifying and lengthening the conjugated branches, even larger TPA cross-sections should be attainable. ${ }^{25}$

Acknowledgment. We acknowledge financial support from CNRS (ATIP and NOI programs), and Rennes Métropole. L. P. and M. C. received fellowships from MENRT and DGA, respectively. We thank K. Rousseau and E. Ronceray for assistance in the synthesis. Calculations were supported by the "Centre Informatique National de 1'Enseignement Supérieur” (CINES-France).

Supporting Information Available: Computational details. Photophysical methods (absorption, fluorescence and TPEF). Description of all new fluorophores. This material is available free of charge via the Internet at http://pubs.acs.org.

(1) (a) Maruo, S.; Nakamura, O.; Kawata, S. Opt. Lett. 1997, 22, 132-134; (b) Cumpston, B. H.; Ananthavel, S. P.; Barlow, S.; Dyer, D. L.; Ehrlich, J. E.; Erskine, L. L.; Heikal, A. A.; Kuebler, S. M.; Lee, I.-Y. S.; McCord-Maughon, D.; Qin, J.; Röckel, H.; Rumi, M.; Wu, X. L.; Marder, S. R.; Perry, J. W. Nature 1999, 398, 51-54; (c) Kawata, S.; Sun, H.-B.; Tanaka, T.; Takada, K. Nature 2001, 412, 697-698; (d) Zhou, W.; Kuebler, S. M.; Braun, K. L.; Yu, T.; Cammack, J. K.; Ober, C. K.; Perry, J. W.; Marder, S. R. Science 2002, 296, 1106-1109.

(2) (a) Parthenopoulos, D. A.; Rentzepis, P. M. Science 1989, 245, 843-845; (b) Strickler, J. H.; Webb, W. W. Opt. Lett. 1991, 16, 17801782; (c) Dvornikov, A. S.; Rentzepis, P. M. Opt. Commun. 1995, 119, 341-346; (d) Belfield, K. D.; Schafer, K. J. Chem. Mater. 2002, 14, 3656-
3662; (e) Belfield, K. D.; Liu, Y.; Negres, R. A.; Fan, M.; Pan, G.; Hagan, D. J.; Hernandez, F. E. Chem. Mater. 2002, 14, 3663-3667.

(3) (a) He, G. S.; Xu, G. C.; Prasad, P. N.; Reinhardt, B. A.; Bhatt, J. C.; Dillard, A. G. Opt. Lett. 1995, 20, 435-437; (b) Ehrlich, J. E.; Wu, X. L.; Lee, I.-Y. S.; Hu, Z.-Y.; Röckel, H.; Marder, S. R.; Perry, J. W. Opt. Lett. 1997, 22, 1843-1845.

(4) Bhawalkar, J. D.; Kumar, N. D.; Zhao, C. F.; Prasad, P. N. J. Clin. Laser Med. Surg. 1997, 15, 201-204.

(5) (a) Denk, W.; Strickler, J. H.; Webb, W. W. Science 1990, 248 , 73-76; (b) Xu, C.; Zipfel, W.; Shear, J. B.; Williams, R. M.; Webb, W. W. Proc. Natl. Acad. Sci. U. S. A. 1996, 93, 10763-10768; (c) Larson, D. R.; Zipfel, W. R.; Williams, R. M.; Clark, S. W.; Bruchez, M. P.; Wise, F. W.; Webb, W. W. Science 2003, 300, 1434-1437.

(6) (a) He, G. S.; Yuan, L.; Cheng, N.; Bhawalkar, J. D.; Prasad, P. N.; Brott, L. L.; Clarson, S. J.; Reinhardt, B. A. J. Opt. Soc. Am. B 1997, 14, 1079-1087; (b) Belfield, K. D.; Hagan, D. J.; Van Stryland, E. W.; Schafer, K. J.; Negres, R. A. Org. Lett. 1999, 1, 1575-1578; (c) Belfield, K. D.; Schafer, K. J.; Mourad, W.; Reinhardt, B. A. J. Org. Chem. 2000, 65, 4475-4481; (d) Abbotto, A.; Beverina, L.; Bozio, R.; Bradamante, S.; Ferrante, C.; Pagani, G. A.; Signorini, R. Adv. Mater. 2000, 12, 1963-1967; (e) Antonov, L.; Kamada, K.; Ohta, K.; Kamounah, F. S. Phys. Chem. Chem. Phys. 2003, 5, 1193-1197.

(7) (a) Reinhardt, B. A.; Brott, L. L.; Clarson, S. J.; Dillard, A. G.; Bhatt, J. C.; Kannan, R.; Yuan, L.; He, G. S.; Prasad, P. N. Chem. Mater 1998, 10, 1863-1874; (b) Kim, O.-K.; Lee, K.-S.; Woo, H. Y.; Kim, K.-S.; He, G. S.; Guang, S. H.; Swiatkiewicz, J.; Prasad, P. N. Chem. Mater. 2000, 12, 284-286; (c) Strehmel, B.; Sarker, A. M.; Detert, H. ChemPhysChem 2003, 4, 249-259.

(8) (a) Albota, M.; Beljonne, D.; Brédas, J.-L.; Ehrlich, J. E.; Fu, J.-Y.; Heikal, A. A.; Hess, S. E.; Kogej, T.; Levin, M. D.; Marder, S. R.; McCord-Maughon, D.; Perry, J. W.; Röckel, H.; Rumi, M.; Subramaniam, G.; Webb, W. W.; Wu, X.-L.; Xu, C. Science 1998, 281, 1653-1656; (b) Ventelon, L.; Blanchard-Desce, M.; Moreaux, L.; Mertz, J. Chem. Commun. 1999, 2055-2056; (c) Ventelon, L.; Charier, S.; Moreaux, L.; Mertz, J.; Blanchard-Desce, M. Angew. Chem., Int. Ed. 2001, 40, 20982101; (d) Frederiksen, P. K.; Jørgensen, M.; Ogilby, P. R. J. Am. Chem. Soc. 2001, 123, 1215-1221; (e) Ventelon, L.; Moreaux, L.; Mertz, J.; Blanchard-Desce, M. Synth. Met. 2002, 127, 17-21; (f) Mongin, O.; Porrès, L.; Moreaux, L.; Mertz, J.; Blanchard-Desce, M. Org. Lett. 2002, 4, 719-722; (g) Pond, S. J. K.; Rumi, M.; Levin, M. D.; Parker, T. C.; Beljonne, D.; Day, M. W.; Brédas, J.-L.; Marder, S. R.; Perry, J. W. J. Phys. Chem. A 2002, 106, 11470-11480; (h) Abbotto, A.; Beverina, L.; Bozio, R.; Facchetti, A.; Ferrante, C.; Pagani, G. A.; Pedron, D.; Signorini, R. Org. Lett. 2002, 4, 1495-1498; (i) Yang, W. J.; Kim, D. Y.; Jeong, M.-Y.; Kim, H. M.; Jeon, S.-J.; Cho, B. R. Chem. Commun. 2003, 2618-2619; (j) Iwase, Y.; Kamada, K.; Ohta, K.; Kondo, K. J. Mater. Chem. 2003, 13, 1575-1581.

(9) (a) Joshi, M. P.; Swiakiewicz, J.; Xu, F.; Prasad, P. N.; Reinhardt, B. A.; Kannan, R. Opt. Lett. 1998, 23, 1742-1744; (b) Chung, S.-J.; Kim, K.-S.; Lin, T.-C.; He, G. S.; Swiatkiewicz, J.; Prasad, P. N. J. Phys. Chem. B 1999, 103, 10741-10745; (c) He, G. S.; Swiatkiewicz, J.; Jiang, Y.; Prasad, P. N.; Reinhardt, B. A.; Tan, L.-S.; Kannan, R. J. Phys. Chem. A 2000, 104, 4805-4810; (d) Cho, B. R.; Son, K. H.; Sang, H. L.; Song, Y.-S.; Lee, Y.-K.; Jeon, S.-J.; Choi, J. H.; Lee, H.; Cho, M. J. Am. Chem. Soc. 2001, 123, 10039-10045; (e) Beljonne, D.; Wenseleers, W.; Zojer, E.; Shuai, Z.; Vogel, H.; Pond, S. J. K.; Perry, J. W.; Marder, S. R.; Brédas, J.-L. Adv. Funct. Mater. 2002, 12, 631-641.

(10) (a) Chung, S.-J.; Lin, T.-C.; Kim, K.-S.; He, G. S.; Swiatkiewicz, J.; Prasad, P. N.; Baker, G. A.; Bright, F. V. Chem. Mater. 2001, 13, 4071-4076; (b) Drobizhev, M.; Karotki, A.; Kruk, M.; Mamardashvili, N. Z.; Rebane, A. Chem. Phys. Lett. 2002, 361, 504-512; (c) Abbotto, A.; Beverina, L.; Bozio, R.; Facchetti, A.; Ferrante, C.; Pagani, G. A.; Pedron, D.; Signorini, R. Chem. Commun. 2003, 21442145; (d) Yoo, J.; Yang, S. K.; Jeong, M.-Y.; Ahn, H. C.; Jeon, S.-J.; Cho, B. R. Org. Lett. 2003, 5, 645-648; (e) Zhang, B. J.; Jeon, S.-J. Chem. Phys. Lett. 2003, 377, 210-216; (f) Mongin, O.; Porrès, L.; Katan, C.; Pons, T.; Mertz, J.; Blanchard-Desce, M. Tetrahedron Lett. 2003, 44 8121-8125.

(11) (a) McDonagh, A. M.; Humphrey, M. G.; Samoc, M.; LutherDavies, B. Organometallics 1999, 18, 5195-5197; (b) Adronov, A.; Fréchet, J. M. J.; He, G. S.; Kim, K.-S.; Chung, S.-J.; Swiatkiewicz, J.; Prasad, P. N. Chem. Mater. 2000, 12, 2838-2841; (c) Drobizhev, M.; Karotki, A.; Rebane, A.; Spangler, C. W. Opt. Lett. 2001, 26, 1081-1083; (d) Drobizhev, M.; Karotki, A.; Dzenis, Y.; Rebane, A.; Suo, Z.; Spangler, C. W. J. Phys. Chem. B 2003, 107, 7540-7543; (e) Mongin, O.; Brunel, J.; Porrès, L.; Blanchard-Desce, M. Tetrahedron Lett. 2003, 44, 2813-2816. 
Org. Lett., Vol. 6, No. 1, 2004, 47-50, DOI: 10.1021/ol036041s

(12) (a) Stadler, S.; Feiner, F.; Bräuchle, C.; Brandl, S.; Gompper, R. Chem. Phys. Lett. 1995, 245, 292-296; (b) Stadler, S.; Bräuchle, C.; Brandl, S.; Gompper, R. Chem. Mater. 1996, 8, 414-417; (c) Lambert, C.; Gaschler, W.; Schmälzlin, E.; Meerholz, K.; Bräuchle, C. J. Chem. Soc., Perkin Trans. 2 1999, 577-587; (d) Lambert, C.; Gaschler, W. Schmälzlin, E.; Meerholz, K.; Bräuchle, C. J. Chem. Soc., Perkin Trans. 2 1999, 577-587.

(13) Hammett constants: $\sigma_{\mathrm{p}}=0.96$ for $\mathrm{SO}_{2} \mathrm{CF}_{3}$ and $\sigma_{\mathrm{p}}=0.72$ for

$\mathrm{SO}_{2} \mathrm{Me}$ (Hansch, C.; Leo, A.; Taft, R. W. Chem. Rev. 1991, 91, 165-195).

(14) Käpplinger, C.; Beckert, R. Synthesis 2002, 1843-1850.

(15) Nemoto, N.; Abe, J.; Miyata, F.; Shirai, Y.; Nagase, Y. J. Mater. Chem. 1998, 8, 1193-1197.

(16) Nodiff, E. A.; Lipschutz, S.; Craig, P. N.; Gordon, M. J. Org. Chem. 1960, 25, 60-65.

(17) Shirota, Y.; Kobata, T.; Noma, N. Chem. Lett. 1989, 1145 1148.

(18) This is corroborated by HOMO-LUMO calculations, which indicate that a significant electronic redistribution takes place from the core to the branches upon excitation.
(19) Based on the low sensitivity of the one-photon absorption spectra to solvent polarity, we expect the TPA spectra in the NIR region to depend only weakly on solvent polarity, except for possible spectral broadening due to inhomogeneous broadening

(20) Xu, C.; Webb, W. W. J. Opt. Soc. Am. B 1996, 13, 481-491.

(21) This excited state is doubly degenerated and our experimental results are in agreement with models presented in the literature for trigonal octupolar molecules..$^{\mathrm{e}, 22}$

(22) Lee, W.-H.; Lee, H.; Kim, J.-A.; Choi, J.-H.; Cho, M.; Jeon, S.-J.; Cho, B. R. J. Am. Chem. Soc. 2001, 123, 10658-10667.

(23) Such strategy has proven to be valid in the case of nanoscale octupoles derived from triphenylbenzene leading to enhanced first-order hyperpolarizability: Brunel, J.; Mongin, O.; Jutand, A.; Ledoux, I.; Zyss, J.; Blanchard-Desce, M. Chem. Mater. 2003, 15, 4139-4148.

(24) PRL-701: $\sigma_{2}=600 \mathrm{GM}$ at $796 \mathrm{~nm}$ (Z-scan) $;{ }^{9 \mathrm{~b}}$ crystal violet: $\sigma_{2}$ $=1980 \mathrm{GM}$ at $752 \mathrm{~nm},(\mathrm{TPEF}, \phi=0.015) \cdot{ }^{\mathrm{9e}}$ compound 9 from ref. $10 \mathrm{f}: \sigma_{2}$ $=1265 \mathrm{GM}$ at $770 \mathrm{~nm},(\mathrm{TPEF}, \phi=0.80)$.

(25) In particular by replacing the phenyl moieties by a fluorene unit $^{10 \mathrm{f}}$ and/or triple bonds by double bonds (but at the expense of reduced photostability). 